\title{
Complex visual hallucinations in the hemianopic field
}

\author{
HANS W KÖLMEL \\ From the Department of Neurology, Free University of Berlin, Berlin
}

SUMMARY From 120 patients with an homonymous hemianopia 16 experienced complex visual hallucinations in the hemianopic field. The brain lesion was located in the occipital lobe, though damage was not limited to this area. Complex hallucinations appeared after a latent period. They were weak in colour and stereotypical in appearance, which allowed differentiation from visual hallucinations of other causes. Different behaviour after saccadic eye movement differentiated between complex visual hallucinations in the hemianopic field and visual auras of an epileptic origin.

Visual hallucinations which appear in the hemianopic field are not rare in neurological practice. A common problem is differentiation between hallucinations as precursors or equivalents of epileptic seizures and hallucinations as isolated phenomena in the hemianopic field, the sole concern of the current study. A detailed case report published by Seguin in $1886^{1}$ is often cited as one of the first descriptions of visual hallucinations in the hemianopic field. However, this case report illustrates the difficulty involved in a purely phenomenological differentiation between visual hallucinations as epileptic auras and as isolated visual phenomena.

Most of the reported phenomena are visual auras in epileptic seizures. Large series were first presented by Uhthoff ${ }^{2}{ }^{3}$ and by Eskuchen. ${ }^{4}$ A large number of the patients included here certainly suffered from seizure disorders. Henschen ${ }^{5-7}$ did extensive work on visual hallucinations in hemianopic fields. He was less concerned with differentiation between epileptic and non-epileptic phenomena than with the significance of these sensations as localising signs. Descriptions of unilateral visual hallucinations associated with occipital lobe tumours were provided by Allen ${ }^{8}$ and by Horrax and Putnam. ${ }^{9}$ However, only eight of 40 patients in Allen's series reported visual hallucinations, while six described phosphenes. Two patients with complex visual hallucinations experienced auditory hallucinations as well. Thirty eight patients suffered homonymous

Address for reprint requests: Priv Doz Dr Hans W Kölmel, Department of Neurology, Klinikum Charlottenburg, Freie Universität Berlin, Spandauer Damm 130 D 1000 Berlin 19.

Received 21 March 1984 and in revised form 16 May 1984. Accepted 21 May 1984. hemianopia in the course of their illness. It is not clear whether there was a temporal correlation between the onset of the hallucination and the development of a visual defect. The study included patients with tumours extending to the parietal or temporal regions, so that it is not possible to ascertain whether the visual hallucinations were symptoms of a circumscribed brain lesion, limited to the occipital lobe, for example. The study published by Horrax and Putnam ${ }^{9}$ was limited to occipital lobe tumours. According to their findings the authors concluded that tumours limited to the occipital lobe caused "unformed hallucinations". Cushing" and Horrax" studied the influence of temporal lobe tumours on vision. They presumed that complex visual hallucinations suggest a temporal lesion. Gloning et al ${ }^{12}$ studied 106 patients with visual hallucinations of various aetiologies and concluded that complex hallucinations in the hemianopic field have no value in localising intracranial lesion, while those which develop without visual defects suggest a temporal lobe process. Anastasopoulos ${ }^{13}{ }^{14}$ suggested that destruction of visual centers explains the fact that patients with tumours and homonymous hemianopia do not report visual hallucinations.

The significance of visual hallucinations in the hemianopic field as localising signs has been a matter of controversy. Weinberger and Grant ${ }^{15}$ studied a group of patients with chiasmal lesions and concluded that visual hallucinations have little or no localising value. Lance ${ }^{16}$ commented that the results of these were not conclusive in that on the contrary visual hallucinations may have value as localising signs, especially when they appear unilaterally, as in hemianopic fields.

Experimental studies with stimulation of the visual cortex resulted in phosphenes. However, Lö- 
wenstein and Borchardt ${ }^{17}$ observed that increasingly strong stimulation may result in transition from phosphenes to complex visual hallucinations. The latter have been reproduced experimentally at the border of the occipital and temporal regions and in the temporal lobe. Foerster ${ }^{18}$ and Penfield and Perot $^{19}$ have provided extensive reports on these findings. The following study attempts initially to describe complex visual hallucinations in the hemianopic field and to define the pathogenesis of these hallucinations as well as to locate their origins. Visual hallucinations which were interpreted as auras in epileptic seizures were excluded from the study, as were all forms of illusion such as dysmorphopsias, micropsias or macropsias, visual perseveration, monocular diplopia or polyopia of central origin. It should be emphasised that all patients in the study recognised a causal relationship between the visual hallucinations and the visual field defect, and considered the visual phenomena unreal. As a result, the phenomena would be termed pseudohallucinations as defined by Jaspers. ${ }^{20}$

\section{Patients}

One hundred and twenty patients with homonymous hemianopia or quadrantanopia were studied at regular intervals over a period of 6 years. The shortest observation period was not less than one year for an individual patient. Ninety five patients had experienced their loss of vision on the day of their first neurological examination or a few days previously. The remaining 25 patients had experienced their loss of vision one or more years before inclusion in the study. Of these patients 88 had suffered from cerebrovascular disease, 29 space-occupying lesion, and three of the patients had either trauma or infectious disease.

A thorough neurological examination was performed, and ophthalmologic studies included determinations of visual fields with conventional dynamic perimetry (Goldmann perimeter), tests of visual acuity and foveal colour recognition using Ishihara charts, as well as measurement of macular vision (tangent screen) in selected cases.

Cranial computed tomography was performed in almost all cases in order to determine cause and location of the brain lesion. Electroencephalograms were recorded in some patients, though never while the patient experienced complex visual hallucinations.

\section{Methods}

With the exception of the study by Lance ${ }^{16}$ there are no systematic investigations of complex hallucinations in the hemianopic field in the literature. Our personal interviews were adapted to the personalities of the individual patients, their power of observation, their anxiety and the type of complex hallucinations which they experienced. All patients were initially informed of the possibility of such sensations before they reported on their own experiences. We conducted an unstructured interview based on the fol- lowing questions:

1 When did the visual field defect or disorder of vision occur and when were hallucinations first observed?

2 During what period of time were hallucinations observed? How long did the individual sensations last?

3 How often did the hallucinations occur, and did they occur regularly?

4 In which part of the visual field were the hallucinations observed?

5 Were the hallucinations coloured or not?

6 Were the hallucinations moving or static? When motion was observed, was it always in the same direction?

7 Was there a variety of hallucinations, or were they always identical?

8 Were the objects in the hallucination of normal size, or did they appear smaller or larger than normal? Were they deformed?

9 Was the content of the hallucinations in any way familiar? What associations were recognised?

10 Was it possible to influence the hallucinations in any way? How did opening or closing the eyes influence them? What happened to the hallucinations when the eyes were moved, or when a near or distant point was fixed?

11 Did the patient suspect the cause of his visual hallucinations?

12 When were the hallucinations last experienced?

During the interviews the patients attempted to convince the interviewer of the insignificance of the visual hallucinations. Each question on the part of the interviewer wasi countered with another question from the patient. The majority of the latter became increasingly mistrustful as the interviewer's questions became more precise.

\section{Case reports}

\section{Static hallucinations}

Case 4 This 68-year-old patient was righthanded and had undergone surgery for recurrence of an oligodendroglioma in the left parieto-occipital region. Homonymous hemianopia was an unavoidable sequela of the operation, since growth of the tumour had been extensive. The visual field defect remained unchanged, while right hemiparesis and amnesic aphasia disappeared completely within a few days of surgery. The patient experienced a variety of coloured and non-coloured phosphenes in the hemianopic field between the second and thirtieth postoperative days. These sensations did not disturb him. In contrast, on the 4th postoperative day he related the strange sensation to a fellow patient and remarked that he thought he was losing his mind. Several small men had suddenly appeared on the right side where he was in fact blind. Approximately twenty figures were standing quite still in a row. Sometimes they appeared in several rows and slightly displaced against one another to form a regular pattern. The figures resembled one another closely, were well dressed and wore top hats like English gentlemen. Their clothing was grey. The faces were not clearly recognizable, and when he tried to fix a single figure all disappeared at once. Any other motion of the eyes or closing the lids caused the figures to disappear. The patient was able to observe these images for up to 30 seconds when he did not look at them directly. The gentlemen appeared five times until the 8th postopera- 
tive day and were never seen again. However, during the next days the patient saw a "fat old lady" who appeared suddenly and at irregular intervals to the right of the midline. She wore a coat and a large hat, was motionless and turned her head slightly away from the patient. After four appearances between the 8 th and 10 th postoperative days the hallucination disappeared for good.

Summary: The patient initially observed a variety of coloured and uncoloured phosphenes. Complex hallucinations were observed independent of the phosphenes between the 4 th and 10 th postoperative days. Two different static colourless figures were observed. The appearance of multiple identical objects resulted in a pattern. Ocular movement caused the sensation to disappear.

\section{Moving hallucinations}

Case 3 This patient was a 66-year-old right-handed female. She appeared well-groomed, self-confident and assured, although a number of chronic illnesses including diabetes mellitus, hyperlipidaemia and hyperuricaemia had caused her problems for a number of years. A cardiac pacemaker had been implanted three years previously. On arising one morning she experienced a sudden violent attack of dizziness accompanied by stabbling pain in the forehead and nausea. Her physician noted elevated blood pressure and prepared an injection of an antihypertensive agent. At the moment of injection the patient saw brilliant flashes of light in the left visual field. The patient described a regular system of bright coloured circles and stars which created a fireworks display. After recovering from her initial shock the patient noticed that the visual sensations had disappeared, but she was blind on the left side.

Determination of the visual fields on the same day revealed complete left homonymous hemianopia with preservation of macular vision. Neurological and neuropsychological findings were normal, while cranial computed tomography demonstrated slight cortical atrophy and a large zone of infarction in the right cortical atrophy occipital region. The EEG 10 days later demonstrated a delta focus in the right temporal region. The visual disorder did not improve. One day after homonymous hemianopia developed, the patient noticed strange sensations in the blind field, but she did not report these experiences for fear that she might be considered mad. She ultimately confided the following: "I often saw hands, which suddenly appeared and approached me from the left. At first they resembled a man's hand, but then they transformed themselves into claws which seemed to want to grasp me. These hands or paws threatened me almost all day long except when I rolled my eyes, which caused the hands to disappear for a short period. On several occasions I also saw approximately 50 peasant women who marched up to me in goose-step. They reminded me of a painting by Hieronymus Bosch. The women were simple in appearance and wore earth-coloured clothing and white caps. For several weeks images resembling birds fluttered past me at eye-level from left to right, but only when I became excited or moved very quickly. Several times three or four animals resembling wolves or foxes appeared on the left. They had reddish bushy tails and stalked silently about my feet. Sometimes they transformed themselves suddenly into snakes and I was so paralysed by fear that I remained seated until they disappeared. I was always convinced that all these apparitions had something to do with my illness and that they were unreal." The events described remained essentially unchanged in appearance over a period of approximately two months. They apeared less often, usually only when the patient became excited, moved quickly or was visited by a man whom she did not like.

Summary: The patient first experienced phosphenes in the left visual field for short periods. On the second day of illness moving hallucinations developed in the blind left field. Four different scenes appeared at irregular intervals. The apparitions moved from the periphery to the center. Colours were seen only once. In one scene multiple images of a single object (the peasant women) appeared. Ocular movement caused the sensations to disappear. The phenomena were observed less often and were limited to specific situations after two months of the illness.

\section{Special types of hallucinations}

\section{Heautoscopia}

Case 6 The patient was an alert and self-possessed 74year-old female with a history of diabetes mellitus for several years. Moderate congestive heart failure had been adequately treated with digitalis. One morning she realised that her vision had deteriorated quite suddenly. Objects appeared blurred and she had the impression of wearing a thin grey veil before both eyes. Left homonymous hemianopia and left hemineglect were diagnosed on the same day. On the second or third day of illness the patient suddenly noticed a seated figure on the left. "It wasn't hard to realise that it was I myself who was sitting there. I looked younger and fresher than I do now. My double smiled at me in a friendly way, as though she wanted to tell me something. It was a rather pleasant experience. I had the opportunity of looking at myself for 10 to 20 seconds and then the image disappeared. The experience was repeated several times over the next seven days. The images changed later, and I saw moving shadows which I could not recognise in place of my own seated image. These apparitions also disappeared on the 12th day of illness." The patient added that one might consider her mad on the basis of this tale. However, she knew that she was not mad and that these visual experiences were merely "marginal appearances". She had the feeling that she had been marked by death.

CT scan demonstrated a large space-occupying hypodense zone in the right parieto-occipital region. Loss of vision remained unchanged for the next few months. The patient was found dead in bed one morning four months after the initial event.

Summary: The patient experienced heautoscopia in the blind field two days after development of homonymous hemianopia. This experience was repeated for approximately nine days and was replaced by moving shadows perhaps phosphenes - for five more days.

\section{Hallucinatory palinopia}

Case 10 The patient was an exceptionally active and healthy 75-year-old man. There was no history of serious illness. He had suffered occipital lobe infarction with right homonymous hemianopia and slight aphasia four years 
earlier. He was referred to the neurology service by an ophthalmologist who had requested an opinion on the patient's homonymous hemianopia.

The patient reported the following: "About four years ago I experienced severe temporal headache on awakening. At the same time I noticed that my vision was impaired, so I took a bus to visit my ophthalmologist. As I looked out the window of the bus, I could not believe my eyes. A gigantic wall of blue tiles stretched from the ground up to the sky. I remembered that these were the same tiles that I had used on the walls of my bathroom four months previously. I wiped my eyes in order to look at the tiled wall more closely, but it disappeared immediately, only to reappear, disappear and reappear once more somewhat later, disturbing both my vision and my state of mind. The same day objects and people appeared suddenly on the right. They were standing or sitting quite still, were rather shadowy and pale in colour. The tiled wall appeared less frequently during the subsequent few days, but I saw a vast landscape in its place. Although I was quite awake, I felt as though I were in a dream and thought that a Fata Morgana in the desert must be similar in appearance. The figures appeared more frequently, and I regretted that they always kept their faces turned away from me and that I could not recognise them. I had the feeling, though, that I had seen many of them before. When I tried to regard a person more closely, he disappeared. I was certain that these apparitions had something to do with my loss of vision and were not real. The figures appeared up to 40 times a day during the following weeks, and irritated me to such an extent that I began to defend myself against them. I either fixed them directly or made gesture in their direction with my hand in order to maintain their irreality. This caused them to disappear. The figures appear rarely now, usually in stress situation.

Summary: Hallucinations first developed in the hemianopic field after a latency period of several hours. They were introduced by hallucinatory palinopia involving objects which the patient had seen several months before. Other static hallucinations began to appear in addition to the palinopia. Ocular movement caused all the hallucinations to disappear. The latter continued to appear in stress situations months after brain infarction.

\section{Results}

Sixteen of 120 patients with homonymous hemianopia or quadrantanopia experienced complex visual hallucinations in the course of their illness (fig 1). Twelve of the 16 patients also suffered other forms of visual delusions such as phosphenes, visual perseveration or monocular diplopia or polyopia, though complex hallucinations never appeared simultaneously with other delusions. Seven patients had left homonymous hemianopia, seven right homonyous hemianopia, one patient had bilateral homonymous hemianopia with preservation of the macular vision and one patient left upper quadrantanopia. Neurological and opthalmological examinations as well as interviews on complex visual hallucinations took place within four days of the onset of the illness in 13 patients, and cranial computed tomography was performed within the first two weeks in these cases. Three other patients were first examined several weeks to 4 years after the onset of homonymous hemianopia. The distribution of different causes is not representative, because vascular brain diseases are over-represented ( 88 out of 120 patients). The cause of hemianopia was brain infarction in 11 cases-including patients with secondary haemorrhage and brain tumour in three other cases, while one patient each suffered from intracerebral or subdural haemorrhage. The occipital lobe was involved in all cases, though other locations were involved in 11 patients, usually the parietal or temporal lobe ipsilateral to the occipital lesion.

Complex visual hallucinations were never experienced at the onset of the visual disorder; hours, days or rarely more than one week passed before the first hallucinations appeared. They always disappeared when hemianopia resolved, at the latest, when the patient could distinguish movements and rough outlines in the visual field ( 5 patients: cases $1,2,12,13$, 15). In cases of persistent visual defects (11 patients), the hallucinations occurred less often in the course of days, weeks or months, and ultimatelyo disappeared, though they sometimes reappeared in situations of physical or emotional stress (fig 2). Higier $^{21}$ reported similar findings. In some cases, it was possible to demonstrate a reduction of the hypo- or hyperdense zone by CT. However in other cases the hallucinations disappeared without it having been possible to show a change in the CT.

The visual hallucinations described by the patients can be divided into two general categories: static apparitions including objects, animals and humans - and moving apparitions involving recognisable stereotypic or complex scenes. The initial hallucinations were static in nine of 16 patients, while moving apparitions subsequently developed. It never happened that an initially static apparition subsequently moved. Ten patients described moving hallucinations, with slow-motion effects in several cases. The apparitions moved from the periphery to the centre of the visual field, where they disappeared, in six patients. Four other patients were unable to describe the direction taken by their visual delusions. All patients reported that ocular movement caused the hallucinations to disappear rather than to wander like retinal after-images. According to self-observations by patients saccadic eye movements were necessary in the course of which it was immaterial whether the eyes were moved towards or away from the hallucinations. They did not disappear, if slow pursuit eye movements are carried out, as for instance if the patient slowly looked in the 


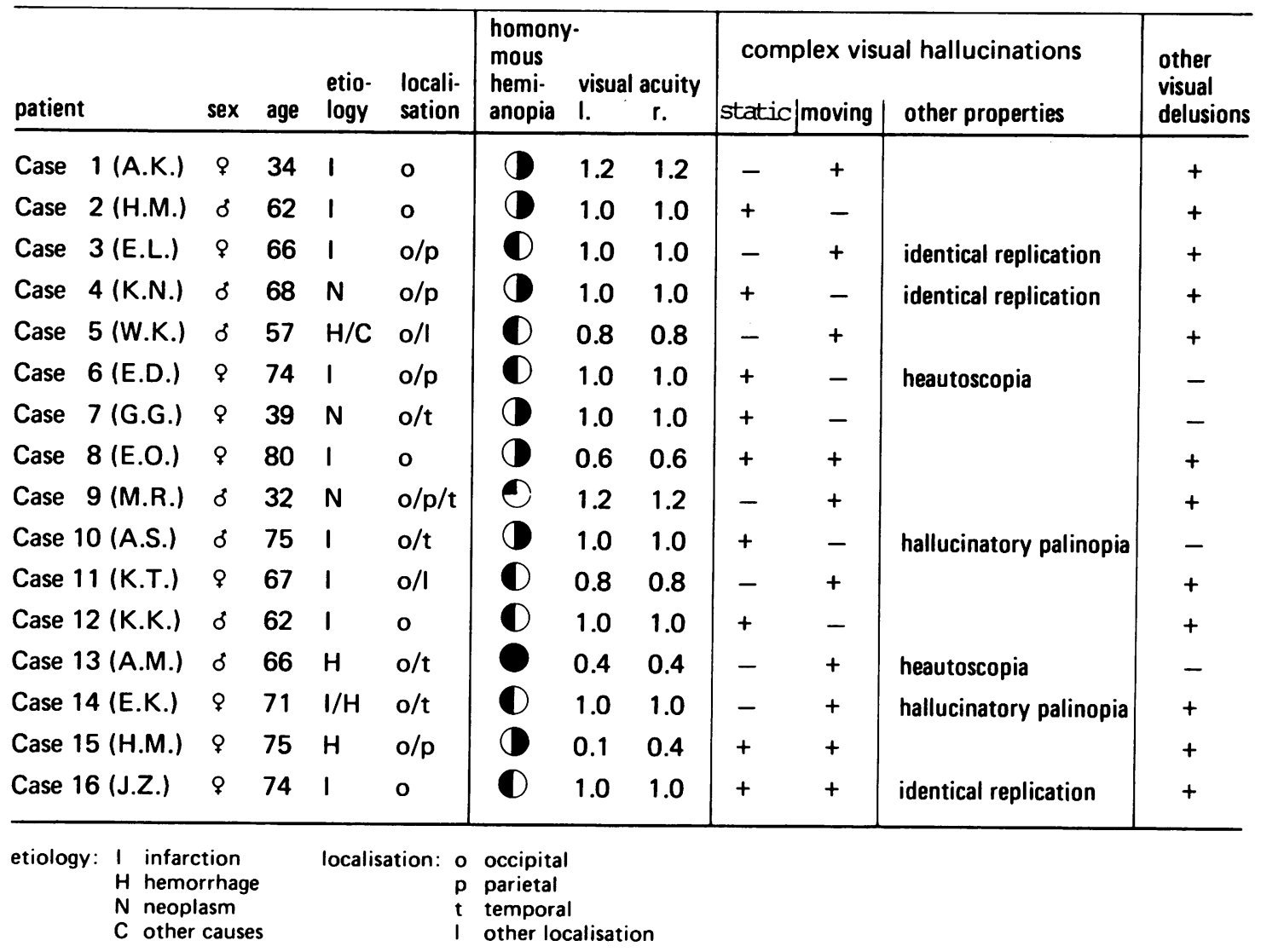

Fig 1 Synopsis of clinical data from 16 patients with complex hallucinations

direction of the hallucinations. Two patients also reported that closing their eyes could make the hallucinations disappear.

The hallucinations did not usually fill the entire visual field. The apparitions were always recognisable entities, though they sometimes represented a part of another entity, such as the head or face of a person. None of the 16 patients reported halved pictures in the hemianopic field as described by Lhermitte. ${ }^{22}$ The objects seen were often somewhat reduced in size and usually pale or colourless. When persons appeared, their faces were difficult to recognise or turned away from the observer. Many patients suffered from the feeling of being helplessly subject to their hallucinations. Almost all patients reported repeated exposure of the same object or scene.

The hallucinations were generally entirely foreign to the patients, who described a feeling of "jamais vu". They were usually able to describe the appari- tions as unreal and associated with the disorder of vision.

A special form of hallucination involved the apparition of objects or persons seen weeks, months or even years in the past. We designate these apparitions as hallucinatory palinopias and differentiated them from genuine palinopias as special types of illusion. The patient may even see himself, which is termed heautoscopia, a special type of hallucinatory palinopia, since the self-image is usually younger and was registered in the visual memory at an earlier time.

A characteristic of some hallucinations was the appearance of multiple identical replication of an object in the form of a pattern which may fill a great part of the hemianopic field. Such identical replications must be separated from the monocular diplopia and polyopia described by Hoff and Pötzl ${ }^{23}$ and by Bender et al. ${ }^{24}$ Diplopia and polyopia are types of illusions, delusions which are generated by 


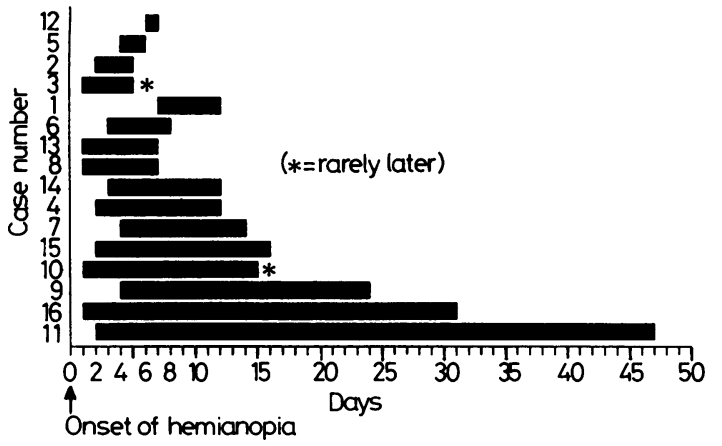

Fig 2 Period of time over which complex hallucinations were experienced. ${ }^{*}=$ and later, on occasion

an external visual stimulus. Although they can appear in the hemianopic field they are, in psychoand physiopathology, different phenomena from the identical replications described.

\section{Discussion}

\section{Location of the brain lesion}

Evaluation of the pathophysiology of complex visual hallucinations and associated brain lesions reveals that the locations of the brain damage, and of stimulation and perception are usually not identical. One might assume that the parietal and temporal brain regions would be involved, since the visual association cortex is located there and since complex visual hallucinations result when these areas are stimulated, though this phenomenon was demonstrated only in patients with epilepsy and only the aura was elicited. ${ }^{25}$ In eight of 13 patients with complex visual hallucinations in the hemianopic field Lance ${ }^{16}$ found damage which was limited to the occipital lobe.
When three patients in this series who obviously experienced visual hallucinations as part of an epileptic seizure are eliminated, the location of the damage can be narrowed down even further to the occipital lobe: eight of 10 patients had such a finding.

All the patients in our study also showed occipital lesions (fig 3). The question is, which criteria must be fulfilled in order for occipital brain damage to be the starting point for the stimulus generating complex visual hallucinations. Clinical and CT findings did not demonstrate whether area 17 alone was involved, whether damage extended to prestriate fields, or whether subcortical damage was decisive. In a preceding study ${ }^{26}$ the lesion was determined by CT in patients who perceived specific coloured phosphenes in hemianopic fields. This area was small and restricted to the striate cortex and the adjacent white matter. In the present study the lesions in the occipital lobe were usually extensive in the CT, although small lesions in the white matter were found in some patients (case 1 for example). But it is not only the extent of the occipital lesion which is noticeable. In addition five patients showed oedema which partly extended as far as the temporal lobe and 10 patients besides to their occipital lesion, had homolateral lesion usually located in theo parietal or temporal lobe. In every case predominantly subcortical structures were affected.

To summarise, two morphological findings are significant in generating complex visual hallucinations: on the one hand the occipital lesion, which causes the hemianopia and interrupts the physiological flow of visual information to the parietal and temporal lobe, on the other hand the more rostraly located lesion, mainly subcortically which mobilises endogenous visual images. Why so many patients with homonymous hemianopia and simlar extent of
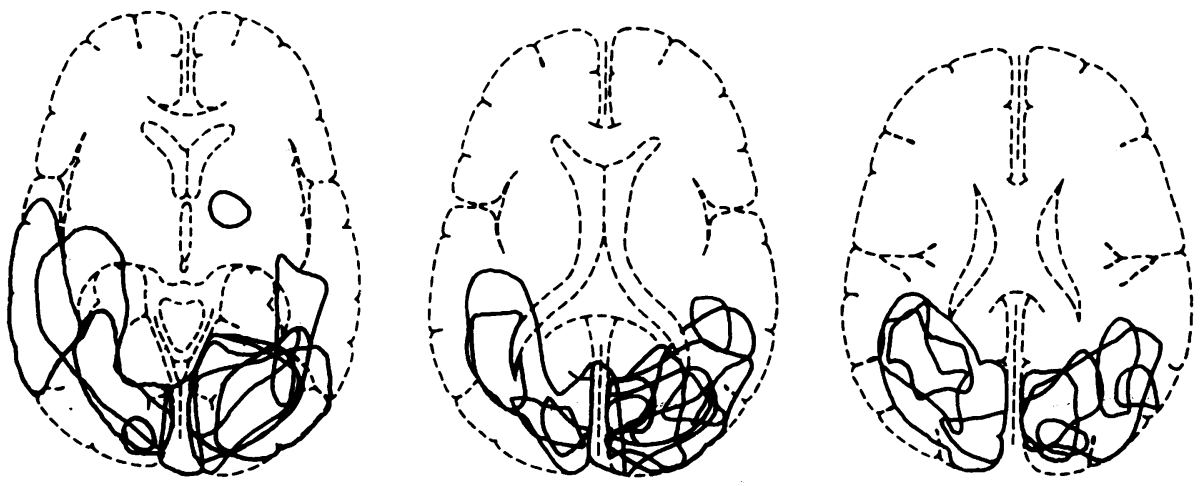

Fig 3 Superimposition of computed tomograms from 16 patients with complex hallucinations in the hemianopic field. 
brain lesions do not experience complex visual hallucinations remains unsolved. Presumably, the premorbid personality, quite independent of the cerebral lesion, has a decisive influence on whether visual hallucinations occur or not. The deprivation experiments performed by Leff ${ }^{27}$ demonstrated that hallucinations are more common in patients with high schizoid factors as measured with the MMPI. These studies correlated well with observations by Horowitz ${ }^{28}$ who reported that patients with schizophrenia demonstrated a pronounced tendency to elaborate phosphenes into complex visual hallucinations. Until now no systematic investigations has been made into the personality profiles of the patients who perceive complex visual hallucinations in the hemianopic field. Hoff and Pötzl ${ }^{23}$ believed that purely complex visual hallucinations in the hemianopic field suggested a lesion limited to the occipital lobe. They assumed that the lesion extended to the temporal region when other sensations, especially auditory hallucinations, occurred. The patients in our series never reported non-visual hallucinations. As a result, the principles espoused by Hoff and Pötzl for topographic differentiation of these lesions were not applicable to our patients. We believe that the extent of damage in the occipital, parietal or temporal regions is less decisive than the extent of neuronal activation resulting from the lesion. A measure of activation is possibly the absence or presence of motion in complex hallucinations. We suspect that perception of single static objects reflects limited neuronal activation while moving objects, persons or scenes imply greater activity. Several patients initially experienced static hallucinations but had hallucinations with movement-with different content-later in their illness. The opposite was never true. We believe that this indicates that neuronal activity had increased, perhaps as a result of facilitation. Furthermore, one could assume the stimulation of an area in which movement is codified. However then it still remains unclear why static hallucinations are perceived first and the mobile ones are only seen after them.

There is no doubt that visual hallucinations can also be caused by strictly temporal lesions, but this type of hallucination almost always appears in the entire visual field rather than in the hemifield. Penfield and Perot ${ }^{19}$ did not find that visual hallucinations resulting from temporal stimulation were perceived contralaterally. Since the authors emphasised the fact that phosphenes and complex visual hallucinations were experienced unilaterally after occipital stimulation, one may assume that the patients experienced the hallucinations in the entire visual field or directly before their eyes. Results published by. Sanford and Bair, Anastasopoulos ${ }^{13} 14$ and
Gloning et al..$^{12}$ suggest that the visual hallucinations associated with temporal lesions are more common when no visual field defects are found. These phenomena are usually part of epileptic seizures and disappear when a visual defect develops.

Teuber $^{30}$ concluded that visual hallucinations are more common in brain lesions on the right side, which implies a certain degree of dominance of the right hemisphere in the development of visual hallucinations. Lance ${ }^{16}$ reported similar findings. In his series of 13 patients, nine had brain lesions on the right. The author concluded that the dominance of visual hallucinations was related to the special characteristics of the right parietal cortex in dealing with visual signals. The author's assumption of a dominant right hemisphere for visual hallucinations corresponds to the results achieved with stimulation of the temporal region reported by Penfield and Perot. ${ }^{19}$ The temporal region in which visual hallucinations were evoked was larger on the nondominant than on the dominant side. However, when one considers only the cases in which complex visual hallucinations were experienced in the hemianopic field-the object of our study-there was no evident predilection for one hemisphere. Seven of our 16 patients had brain lesion on the left, eight on the right and one had bilateral damage. Figure 3 demonstrates the brain lesion in this series.

Perception of multiple identical replications of a single object or a person, whether static or moving, is a special type of complex visual hallucinations. Such a type of replication is not identical to the diplopia or polyopia described by Hoff and Pötzl ${ }^{23}$ and by Bender et al.$^{24}$ Diplopia and polyopia are special forms of illusion. Hallucinatory identical replication demonstrates a synchroneous systematic repetition of a visual image, rather like the prismatic splitting of a beam of light. Where such a splitting is generated remains unclear. In its stereotype-best illustrated by the wallpaper pattern described in case 4 -identical reduplication resembled coloured patterns in the hemianopic field, described by Kölmel, ${ }^{26}$ which were interpreted as an expression of the functional architecture of the primary visual cortex. It is conceivable that identical replication represents a complex correlative to such an architecture.

\section{Ocular movement}

Complex visual hallucinations disappear when the patient carries out saccadic eye movement. In this it is immaterial whether the patient looks towards or away from the hallucinated image. However, it is normal for the patient to look in the direction of the hemianopic field, that is, at the hallucinations. From the descriptions it may be concluded that saccades are necessary and that 
pursuit movements do not have any effect. Our investigations could not sufficiently determine to what extent closing the eyes could make hallucinations disappear in the same way. All patients already noticed after a short time the extinguishing effect of the saccadic eye movements and made use of them in order to free themselves of the increasingly burdensome visual hallucinations. Hoff and Pötzl ${ }^{23}$ reported observations similar to our own. In assessing the influence of saccadic eye movements, it is necessary to differentiate carefully between visual hallucinations and other delusions in the hemianopic field. Some types of illusions such as palinopia and monocular diplopia or polyopia experience a translocation synchronous with the saccades and consequently do not behave in the same way as the complex hallucinations. ${ }^{23} 24$

Visual hallucinations of an epileptic nature demonstrate a dynamic of their own and can seldom or never be influenced by arbitrary ocular movements, and we think that this different behaviour offers a decisive opportunity to differentiate between complex visual hallucinations in the hemianopic fields and epileptic visual auras. However, from the numerous case histories ${ }^{181931}$ it has not been shown conclusively, how epileptic visual auras, especially the ones which occur in the hemianopic fields, actually behave after saccadic ocular movements. Either the hallucinations last for too short a period of time for the influence of saccades to be tested or else a tonic deviation of the eyes in the direction of the hallucination occurs, a deviation which cannot be suppressed and which frequently leads to a complex focal or a grand mal seizure. If the saccadic eye movement had a suppressive effect on the epileptic visual aura similar to that which they have on complex visual hallucinations in the hemianopic fields, one could assume that both groups of patients would go through a learning process in comparatively the same time. However it happens rarely that patients with epileptic visual aura learn to cut short an attack at will.

There are several possible hypotheses for an interpretation of the saccadic extinction effect. Phosphenes in the visual hemifield caused by cortical stimulation move with eye movement as do retinal after-images ${ }^{32}$ and are not extinguished by eye movement. They arise in cortical regions related to the retinal projection and are suppressed only by local inhibition. Stimuli which cause complex visual hallucinations in the hemianopic field originate in the occipital lobe, but they represent extensive and complex, easily disturbed activity which may extend to the parietal and temporal regions. One may initially assume that eye movement represents highly ordered volitional activity capable of suppressing the unstable neuronal activity generating complex visual hallucinations. The arousal effect of the saccades remains independent of whether the eyes are turned away from real visual objects or from the endogenous images. Munson and Schwartz ${ }^{33}$ suggested, on the basis of their experimental results with cats, that those ponto-geniculo-occipital waves recorded during arousal have the physiological significance of increasing visual function at the moment of cessation of the saccade. If this proves to be true, an inhibitory effect on what had been seen previously, both on the objective and on the endogenous images, that is on the visual hallucinations would be conceivable. An inhibitory effect on the visual input is also attributed to those lambda waves, which can be recorded in the human occipital lobe during saccadic eye movements. ${ }^{34}$

Extinction of complex visual hallucinations in hemianopic fields by saccadic eye movements reminds one the shift effect, interpreted as a retinal function by Krüger and Fischer. ${ }^{35}$ Each change of fixation causes extinction of the last retinal image in order that the new, current image can be received. In addition unnecessary perception of the visual world inside the saccade does not occur, and the retina is prepared for development of the nexP image. One could postulate that with retinal dis尺 charge, via the lateral geniculate nucleus and othe $\vec{g}$. thalamic relay stations inhibitory impulses reacto those cortical fields or subcortical regions which ares responsible for generation of complex visual halo lucinations.

Recently the significance of the extraocular muse cles for the visual system has been seen in a new light. One can assume that inhibitory impulses starting from the proprioceptors of the extraocular muscles reach the cortex via the superior colliculi during saccades, as Donaldson and Lond ${ }^{36}$ were able to demonstrate on cats. The impulses, which must make a considerable contribution to the stability of the visual world would also be responsible for the extinction of the visual hallucinations. In that sense it does not really matter whether visual perception proceeds via physiological retinal afferences or whether it is triggered off via a pathological cortical and/or subcortical irritation.

\section{Stimulus or release symptom}

The unconscious apparently takes advantage of the opportunity to supply visual images to the dark half field without reference to origin and location of homonymous hemianopia. The personality structure as well as the sum of visual experience in the memory and the patient's ability to mobilise this experience when normal stimuli are absent determine the appearance of complex hallucinations. It is not sur- 
prising that complex visual hallucinations occur in deprivation experiments, ${ }^{37}{ }^{38}$ after enucleation of an eye, ${ }^{39}$ in blindness, ${ }^{40}$ as well as in brain lesions located near the chiasma, the optic tract and the temporal or occipital regions.

Weinberger and Grant ${ }^{15}$ assumed that all complex visual hallucinations were similar regardless of their origin. As a result, these authors ascribed no significance to complex hallucinations in localising brain lesion. However, when one examines the phenomenology of visual hallucinations of various origins two distinct groups are found. In the first category the hallucinations experienced by a single person are extremely varied, in contrast to the second category, in which the hallucinations remain rather constant. Cogan ${ }^{41}$ characterised the hallucinations experienced by the first group as release phenomena, in contrast to the stimulation phenomena experienced by the second group. In general, stimuli are characterised by the response to them, which tend to be stereotyped, to follow the stimulus and disappear when the stimulus is absent or below a given threshold. In addition, these phenomena are exhaustible, and refractory periods are found between responses. Release phenomena are not stereotyped; on the contrary, they may demonstrate considerable variety. They generally develop slowly, last for varying periods of time and slowly decline. In this sense, the highly varied hallucinations which accompany enucleation of an eye or late blindness must be considered release phenomena. As Weinberger and Grant ${ }^{15}$ concluded, these perceptions have little significance in localising brain lesions. Stereotyped repetitive and identical visual hallucinations in the aura of an epileptic seizure are further examples of excitation phenomena. Their significance as localising symptoms is well documented. It is more difficult to categorise complex visual hallucinations in the hemianopic field. The latency period between onset of the visual defect and initial appearance of the hallucinations is characteristic of release phenomena. It may be that this period represents a necessary phase in which the visual defect is registered and appropriated as a projection field. The long duration and gradual appearance and disappearance of visual sensations is also characertistic of release phenomena. In contrast, the stereotyped character of the hallucinations - the same landscape in case 10, repetition of the double sitting on a chair in case 6, reapparition of the gentlemen in case 4-suggests stimulation such as encountered in the visual auras of epileptic seizures.

Complex visual hallucinations in the hemianopic field may be interpreted as combined stimulation and release phenomena and differentiated from pure stimulation phenomena such as the aura of epileptic seizures as well as from pure release phenomena appearing as visual hallucinations in cases of extracerebral visual disorders.

\section{References}

'Seguin EG. A contribution of the pathology of hemianopsis of central origin (cortex-hemianopsia). $J$ Nerv Ment Dis 1986;13:1-38.

2 Uhthoff W. Beiträge zu den Gesichtstäuschungen bei Erkrankungen des Sehorgans. Mschr Psychiatr Neurol 1899; 3:241-64, 370-9.

${ }^{3}$ Uhthoff W. Beiträge zu den hemianopischen Gesichtsfeldstörungen nach Schädelschüssen, besonders solcher im Bereich des Hinterhauptes. Monatsblätter f. Augenheilkunde 1915;55:104-125.

4 Eskuchen E. Über halbseitige Gesichtsfeldhalluzinationen und halbseitige Sehstörungen. Inaug.-Diss. Heidelberg 1911.

${ }^{5}$ Henschen SE. Beiträge zur Pathologie des Gehirns Uppsala 1890/1892.

- Henschen SE. Vierzigjähriger Kampf um das Sehzentrum und seine Bedeutung für die Hirnforschung. $Z$ ges Neurol Psychiat 1923;87:505-35.

${ }^{7}$ Henschen SE. Über die Lokalisation einseitiger Gesichtshalluzinationen. Arch Psychiat Nervenkr 1925;75:630-55.

8 Allen IM. A clinical study of tumours involving the occipital lobe. Brain 1930;53:194-243.

${ }^{9}$ Horrax G, Putnam TJ. Distortion of the visual fields in cases of brain tumor. The field defects and hallucinations produced by tumours of the occipital lobe. Brain 1932;55:499-523.

${ }^{10}$ Cushing $\mathrm{H}$. The field defects produced by temporal lobe lesions. Brain 1921;44:341-96.

"Horrax G. Visual hallucinations as a cerebral localizing phenomenon, with especial reference to their occurrence in tumors of the temporal lobe. Arch Neurol Psychiat 1923; 19:532-47.

12 Gloning I, Gloning K, Hoff H. Über optische Halluzinationen. Wiener $Z$ Nervenhk 1967;25:1-19.

13 Anastasopoulos G. Zur Frage der hemianopischen Halluzinationen der Orientierungsstörung und der optischen Allästhesie. W Zschft Nervenheilk 1952;6:3448.

14 Anastasopoulos G. Beiträge zu den Halluzinationsproblemen. Psychiat Neurol 1962;143:233-49.

is Weinberger EA, Grant FC. Visual hallucinations and their neuro-optical correlates. Arch Ophthalmol 1940;23:166-99.

${ }^{16}$ Lance JW. Simple formed hallucinations confined to the area of a specific visual field defect. Brain 1976;99:719-34.

17 Löwenstein K, Borchardt M. Symptomatologie und elektive Reizung bei einer Schussverletzung des Hinterlappens. Dtsch Z Nervenheilk 1918;58:264-92.

18 Foerster O. Beiträge zur Pathophysiologie der Sehsphäre. J Psychol Neurol 1929;39:463-85.

19 Penfield W, Perot P. The Brain's record of auditory and visual experience. Brain 1963;86:596-696.

${ }^{20}$ Jaspers K. Allgemeine Psychopathologie. Berlin, Springer 1973. 
${ }^{21}$ Higier H. Über unilaterale Halluzinationen. Wien Klinik 1894;20:139-70.

${ }^{22}$ Lhermitte J. Les Hallucinations Clinique et Physiopathologie. Paris, Doin 1951.

${ }^{23}$ Hoff H, Plötzl O. Über. Polyopie und gerichtete hemianopische Halluzinationen. Jahrbücher für Psychiatrie 1937;54:55-88.

${ }^{24}$ Bender MB, Feldman M, Sobin AJ. Palinopsia. Brain 1968;91:321-38.

${ }^{25}$ Penfield W, Rasmussen T. The Cerebral Cortex of Man. New York Macmillan 1952:135-47, 165-6.

${ }^{26} \mathrm{Kölmel} \mathrm{HW}$. Coloured patterns in hemianopic fields. Brain 1984; 107:155-67.

${ }^{27}$ Leff JP. Perceptual phenomenia and personality in sensory deprivation. Br J Psychiat 1968;114:1499-508.

${ }^{28}$ Horowitz MJ. The imagery of visual hallucinations. $J$ Nerv Ment Dis 1964;138:513-23.

${ }^{29}$ Sanford HS, Bair HL. Visual disturbances associated with tumors of the temporal lobe. Arch Neurol Psychiat 1939;42:21-43.

${ }^{30}$ Teuber HL. Effect of brain wounds implications right or left hemisphere in Man. In: Mountcastle VB, ed. Interhemispheric Relations and Cerebral Dominance. Baltimore, John Hopkins Press, 1961.

${ }^{31}$ Russel WR, Whitty CWM. Studies in traumatic epilepsy, III. Visual fits. J Neurol Neurosurg Psychiat 1955; 18: 79-96.

${ }^{32}$ Brindley GS, Lewin $W$. The sensations produced by electrical stimulation of the visual cortex. J Physiol (Lond) 1968;196:479-83.

${ }^{33}$ Munson JB, Schwartz KS. Lateral geniculate and occipital cortex spikes with eye movements in awake and sleeping cats: temporal and functional correlations. Exp Neurol 1972;35:300-4.

${ }^{34}$ Kurtzberg D, Vaughan HG. Electrophysilogical observations on the visumotor system and visual neurosensorium. In: Desmedt JE, ed, Visual Evoked Potentials in Man: New Developments. Oxford, Clarendon Press, 1977:314-31

${ }^{35}$ Krüger J, Fischer B. Strong periphery effect in cat retinal ganglion cells. Exitatory responses in on- and offcenter neurones to single grid displacements. Exp Brain Res 1973;18:316-8.

${ }^{36}$ Donaldson IML, Long AC. Interactions between extraocular proprioceptive and visual signals in the superior colliculus of the cat. J Physiol (Lond) 1980;298:85110.

${ }^{37}$ Kempe P, Reimer CH. Halluzinatorische Phänomene bei Reizentzug. Nervenarzt 1976;47:701-7.

${ }^{38}$ Zuckermann M. Hallucinations, reported sensations and images. In: Zubeck JP, ed. Sensory Deprivation: Fifteen Years of Research. New York, AppletonCentry-Crofts. 1969:85-125.

${ }^{39}$ Lauber HL, Lewin B. A clinical and psychological study of optic hallucinations in the elimination of vision. Arch Psychiat Nervenkr 1958;197:15-31.

${ }^{40}$ Jacob H. Der Erlebniswandel bei Späterblindeten. Zur Psychopathologie der optischen Wahrnehmung. Abhandlung zur Psychiatrie, Psychologie, Psychopathologie und Grenzgebieten Bd. 1. Hamburg, Nölke Verlag. 1949.

41 Cogan DG. Visual hallucinations as release phenomena. Graefes Arch Klin Opthalmol 1973;188:139-50. 